\title{
ANALISIS SISTEM PENGOLAHAN ABSENSI KARYAWAN PADA PT. BAKRIE SUMATERA PLANTATIONS TBK BUNUT
}

\author{
Muhammad Yasin Simargolang *1, Wiyoga Agung Warsito *2 \\ ${ }^{* 1,2}$ Universitas Asahan; Jln. Jend. Ahmad Yani, Telp/Fax (0623)347222 \\ ${ }^{*} 1,2$. Program Studi Teknik Informatika, Fakultas Teknik UNA, Kisaran Sumatera Utara \\ e-mail: ${ }^{* 1}$ muhammadyasins@ @mail.com,${ }^{2}$ wiyogaagungwarsito29@gmail.com,
}

\begin{abstract}
Abstrak - Perkembangan teknologi informasi dari tahun ketahun yang semakin cepat menjadi tantangan berat bagi pengguna teknologi informasi itu sendiri dan mendorong setiap sector organisasi baik formal maupun informal atau lembaga-lembaga lainnya untuk dapat memanfaatkannya sebagai penunjang kegiatan kerja sehingga dapat menghasilkan informasi yang cepat, tepat dan akurat. PT. Bakrie Sumatera Plantations Tbk Bunut sebagai perusahaan di bidang pengolahan sawit dan karet tentu saja memerlukan manajemen yang baik dalam mengelola data absensi karyawannya yang nantinya akan berdampak positif bagi perkembangan perusahaan itu sendiri. Maka dibutuhkan informasi yang efisien dalam mempertahankan keberadaannya agar tetap eksis dan dikenal oleh masyarakat luas. Salah satu upaya untuk mendukung hal itu adalah sistem komputer yang baik. Untuk mendapat sistem yang baik maka dilakukan penelitian terhadap sistem yang sudah ada. Tahap berikutnya adalah melakukan analisis untuk mengetahui kelebihan dan kekurangan sistem tersebut. Kemudian dilakukan perancangan sistem yaitu Flowmap, Data Flow Diagram, dan Diagram Konteks. Dan tahap terakhir yaitu Implementasi yang mengubah perancangan kedalam tahap bahasa pemrograman.
\end{abstract}

Kata kunci - sistem, analisis, absensi

Abstract - The rapid development of information technology from year to year becomes a formidable challenge for information technology users themselves and encourage every sector of the organization either formal or informal or other institutions to be able to use it as a supporter of work activities so as to produce information quickly, precisely and accurately. PT. Bakrie Sumatera Plantations Tbk Bunut as a company in the field of palm and rubber processing of course require good management in managing data absenteeism of employees which will have a positive impact for the development of the company itself. So it takes efficient information in maintaining its existence in order to exist and known by the public. One attempt to support it is a good computer system. To get a good system then do research on existing systems. The next stage is to do an analysis to find out the advantages and disadvantages of the system. Then done system design that is Flowmap, Data Flow Diagram, Entity and Context Diagram. And the last stage is Implementation that changes the design into the stage of programming language.

Keywords - system, analysis, absenteeism

\section{PENDAHULUAN}

\subsection{Latar Belakang}

PT. Bakrie Sumatera Plantations Tbk adalah suatu perusahaan yang bergerak di bidang perkebunan dengan memproduksi karet dan sawit. Intesitas kesibukan para karyawan yang begitu tinggi menuntut perusahaan agar dalam pengolahan data karyawan lebih cepat, akurat, dan efisien. Salah satu sistem informasi yang terdapat pada PT. Bakrie Sumatera Plantations Tbk Bunut tersebut adalah sistem informasi pengolaan data data karyawan Berbasis website dengan menggunakan oracle, untuk pengolahan data rubber, oil palm, absensi, penggajian dan upkeep dalam satu Payroll yang digolongkan sangat penting untuk pencegah terjadinya kesimpang siuran dalam menyelesaikan pengolahan data karyawan tersebut.

Dalam melaksanakan aktivitas sehariharinya, PT. Bakrie Sumatera Plantations Tbk Bunut selalu menggunakan komputer dalam pengolahan data, sama seperti pada instansiinstansi besar swasta lainnya. Pada jaringan PT.Bakrie Sumatera Plantations Tbk terdapat Local Area Network (LAN) dan Internet (Cabling dan Hotspot), hotspot PT. Bakrie Sumatera Plantations dipasang pada area selasar, setiap lantai, setiap gedung, ruang Auditorium dan ruang rapat. Maka salah satu sarana yang mempunyai peranan sangat penting 
dalam melaksakan tugas tersebut adalah jaringan Local Area Network (LAN) dan Wireless Local Area Network (WLAN), karena seperti diuraikan di atas jaringan ini kompatibel di dalam suatu pekerjaan yang membutuhkan desktop, notebook, atau PDA untuk melakukan aktivitas kerja dalam mengolah data, sharing resources maupun mencari informasi penting lainnya. Maka dari itu seberapa pentingnya infrastruktur jaringan yang baik dalam menunjang kelancaran dalam teknologi informasi dan komunikasi (TIK).

Akan tetapi masih ada proses yang dilakukan dengan cara manual yaitu pengiriman data dokumen dari lokasi ke Head office (bagian Payroll) untuk diproses memakai Oracle System. Hal ini tentunya sangat mempengaruhi kinerja kerja di bagian payroll karena harus menginputkan lagi data harian karyawan satu per satu dan pengecekkanya kembali, selain itu sistem itu dengan sistem pengiriman dokumen dari harian yang masih manual ini, data yang dikirimkan menjadi kurang akurat karena masih dalam bentuk berkas tertulis sehimngga dapat mengakibatkan terjadi kesalahan penginputan data karena tulisan tidak jelas, serta keterlambatan dalam pembagian gaji karyawan karena data yang dikirim terlalu lama.

Lamanya data sampai bisa mengakibatkan beberapa faktor diantaranya faktor cuaca buruk dan faktor transportasi, untuk itu penulis mengangkat laporan yang berjudul "Analisis Sistem Informasi Pengolahan Absensi Karyawan Pada PT. Bakrie Sumatera Plantations Tbk Bunut".

\subsection{Pengertian Sistem informasi}

Sistem informasi merupakan peranan yang penting dalam membantu menyediakan informasi untuk berbagai tingkatan manajemen. Sistem yang dibutuhkan adalah sistem yang memperlancar proses kegiatan yang sedang berjalan. Untuk lebih memahami tentang sistem Jugiyanto H.M (2005:11) mengartikan sistem informasi adalah suatu sistem dalam suatu organisasi yang mempertemukan kebutuhan pengolahan transaksi harian, mendukung operasi, sifat managerial dan kegiatan strategi dari suatu organisasi dan menyediakan pihak luar tertentu dengan laporan-laporan yang diperlukan. Sedangkan menurut Witarto (2004:19) sistem informasi merupakan sistem yang berisi SPD (sistem pengolahan data) yang dilengkapi dengan kanal-kanal komunikasi yang digunakan dalam sistem organisasi Data.

\subsection{Elemen Sistem}

Menurut Jugianto H.M (2005:12) Sistem informasi terdiri dari elemen-elemen yang terdiri dari orang, prosedur, perangkat keras, perangkat lunak, basis data jaringan komputer dan komunikasi data. Semua elemen ini merupakan komponen fisik :

1. Orang

Orang atau personal yang dimaksudkan yaitu operator komputer, analisis sistem, programmer, personil data entry dan manager sistem informasi.

2. Prosedur

Prosedur merupakan elemen fisik. Hal ini diseebabkan karena prosedur disediakan dalam bentuk fisik seperti buku panduan dan intruksi.

3. Perangkat Keras

Perangkat keras bagi suatu sistem informasi terdiri atas komputer, peralatan penyimpan data, dan terminal masuk atau keluar.

4. Perangkat Lunak

Perangkat lunak dapat dibagi tiga jenis diantaranya:

a. Sistem perangkat umum, seperti sistem pengoperasian dan sistem manajemen data yang memungkinkan pengoperasian sistem komputer.

b. Aplikasi perangkat lunak umum, seperti model analisis dan keputusan.

c. Aplikasi perangkat lunak yang terdiri atas program yang secara spesifik dibuat untuk setiap aplikasi.

5. Basis data

Menurut Bambang harianto (2004:20): file yang berisi program dan data dibuktikan dengan adanya media penyimpanan secara fisik, seperti disket, harddisk, magnetic tape dan sebagainya. File juga mengikuti keluaran tercetak dan catatan lain diatas kertas, micro film, dan sebagainya. 
6. Jaringan komputer

Menurut Melwin Safrizal (2010:2): jaringan komputer adalah sebuah sekumpulan komputer, printer dan peralatan lainnya yang terhubung dalam satu kesatuan informasi dan data bergerak melalui kabel-kabel atau tanpa kabel sehingga memungkinkan pengguna jaringan komputer dapat saling bertukar dokumen dan data.

7. Komunikasi Data

Menurut Soewarno Handaya Ningrat (1980:94): komunikasi data adalah merupakan bagian dari telekomunikasi yang secara khusus berkenaan dengan transmisi atau perpindahan data dan informasi diantara komputer-komputer dan piranti-piranti yang lain dalam bentuk digital yang dikirimkan melalui media komunikasi data.

\subsection{Database}

Menurut Bambang Harianto(2004:20): Database (Basis data) merupakan kumpulan data yang saling berhubungan. Hubungan antara data dapat ditunjukkan dengan tandanya field kolom kunci dari tiap file/tabel yang ada. Dalam suatu file atau tabel terdapat record-record yang sejenis, sama besar, sama bentuk yang merupakan satu kumpulan entitas yang seragam. Suatu record umumnya digambarkan sebagai baris data terdiri satu field yang berhubungan menunjukkan bahwa field tersebut dalam suatu pengertian yang lengkap dan disimpan dalam satu record. Dalam database sangat mudah di-update dan sangat cepat dicari software atau aplikasi yang bertugas untuk menyimpan, memodifikasi, dan disebut dengan software database engine dan lebih resmi disebut dengan DBMS (Database Management System).

Ada banyak sekali aplikasi DBMS ini mulai yang berjalan di komputer personal (PC) sampai kekomputer skala mainframe contohcontoh dari aplikasi database engine misalnya seperti:

1. SQL Server, dibuat oleh Microsoft

2. MS Access, dibuat oleh Microsoft

3. Oracle Database, dibuat oleh Oracle

4. MySQL, dibuat oleh MySQL

5. Firebird, dibuat oleh Omunitas Open Source berdasarkan kode dari kode interbase
6. PostgreSQL, dibuat oleh komunitas open source

7. DB2, dibuat oleh IBM

Ada banyak sekali aplikasi yang biasa menggunakan database beberapa diantaranya adalah:

1. Sistem perpustakaan yang berbasis komputer, pasti membutuhkan database yang besar untuk merawat data buku yang dimilikinya.

2. Sistem ATM (Automatic Teller Machine) pasti membutuhkan database yang besar untuk mengambil dan mengupdate saldo uang.

3. Sistem reservasi tiket pesawat pasti membutuhkan database untuk menyimpan data reservasi tiket.

Sistem invertory, pasti membutuhkan database untuk menyimpan data inventory termasuk updeting data stok barang dan lain sebagainya.

\section{METODE PENELITIAN}

Metode penelitian disini adalah cara-cara untuk mendapatkan segala informasi yang dibutuhkan dalam penyusunan laporan kerja praktek ini, dan untuk itu digunakan beberapa metode penelitian :

1. Wawancara

Metode ini diterapkan dengan cara melakukan komunikasi langsung dengan responden atau pihak yang bertanggung jawab mengenai masalah yang diteliti, yaitu absensi karyawan PT. Bakrie Sumatera Plantations Tbk Bunut.

2. Observasi Lapangan

Pengumpulan data dilakukan dengan melakukan observasi atau penelitian langsung pada objek penelitian. Riset dilaksanakan dari tanggal 1 Agustus 2017 sampai dengan tanggal 31 Agustus 2017. Waktu riset adalah hari senin - sabtu, selama 1 bulan dimulai dari pukul 07.00 WIB sampai dengan pukul 14.00 WIB.

\section{HASIL DAN PEMBAHASAN}

\subsection{Analisis Sistem (System Analyze)}

Penguraian dari suatu sistem informasi yang utuh kedalam bagian-bagian komponenya dengan maksud untuk mengidentifikasi dan mengevaluasi permasalahan-permasalahan, 
kesempatan-kesempatan, hambatan yang terjadi dan kebutuhan-kebutuhan yang diharapkan sehingga dapat diusulkan perbaikan-perbaikan. Didalam analisis sistem terdapat langkahlangkah dasar yang harus dilakukan oleh analisis sistem yaitu identify, understand, analyze, dan report.

\subsection{Perancangan Sistem (Sistem Designer)}

Perancangan sistem dapat diartikan sebagai berikut:

a. Tahap setelah analisis dari siklus pengembangan sistem.

b. Pendefenisian dari kebutuhankebutuhan fungsional.

c. Persiapan untuk rancangan bangunan.

d. Menggambarkan bagaimana suatu sistem terbentuk.

e. Yang dapat berupa penggambaran, perencanaan dan pembuatan seketsa atau pengaturan dari beberapa elemen yang terpisah kedalam satu kesalahan yang utuh dan berfungsi

f. Termasuk menyangkut konfigurasi dari komponen-komponen perangkat lunak dan perangkat keras dari suatu sistem.

Menggambarkan bagaimana suatu sistem dibentuk yang berupa penggambaran, rancangan, dan pembuatan sketsa atau pengaturan dari beberapa elemen yang terpisah kedalam satu kesatuan yang utuh.

\subsection{Analisis Sistem Informasi Absensi}

Karyawan Yang Sedang Berjalan

Analisis Sistem dapat diartikan sebagai suatu proses untuk memahami sistem yang ada yaitu sistem informasi absensi. Sistem ini meliputi analisis prosedur sistem informasi absensi, flow map sistem informasi absensi, dan analisis dokumen data absensi. Cara pengisian absen dan prosedur pengolahan data sesuai hal yang ditentukan :

1. Nama Karyawan

2. Nomor Induk Karyawan

3. Bagian Karyawan

4. Jam Masuk Karyawan

5. Jam Pulang Karyawan

6. Tanggal Kerja Karyawan

7. Keterangan

\subsection{Flowmap}

Bagian dokumen merupakan diagram yang menunjukkan aliran data berupa formulir ataupun keterangan berupa dokumentasi yang mengalir dalam suatu sistem. Adapun fungsi dari flow map adalah untuk mempermudah penggambaran alira data yang berupa dokumen sistem yang sedang berjalan dapat dilihat pada gambar berikut ini. 
Tabel 3.1 Flow Map sistem yang sedang berjalan

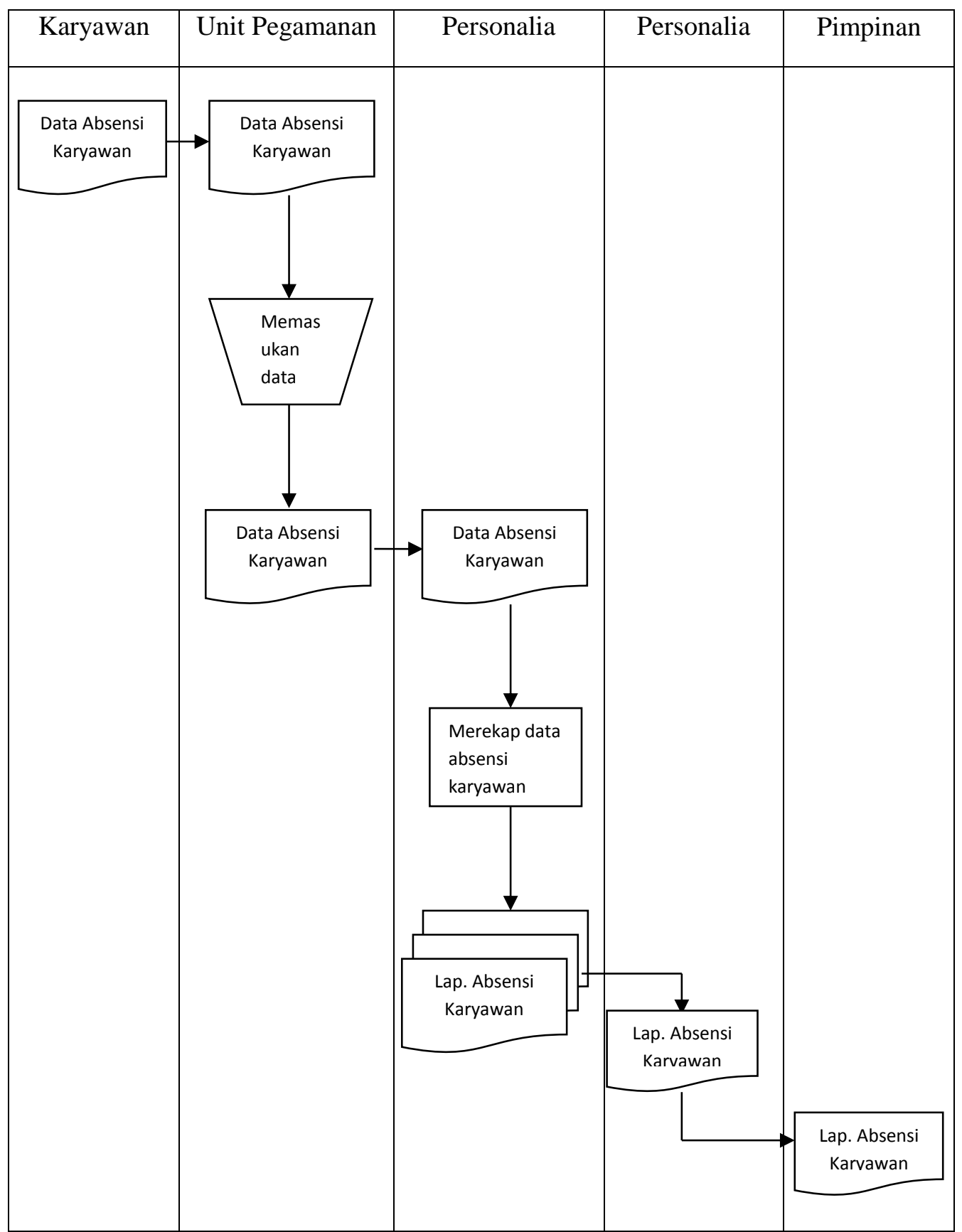

\subsection{Diagram Konteks}

Diagram konteks digunakan untuk menggambarkan aliran-aliran data ke dalam dan keluar sistem atau keluar entitas eksternal yang terletak diluar sistem, tugasnya untuk mempersentasikan kesluruhan sistem dan pembuatan program aplikasi sistem informasi absensi, secara garis besar dirancang dengan memperhatikan masukan yang akan dihasilkan sistem sebagai berikut. 


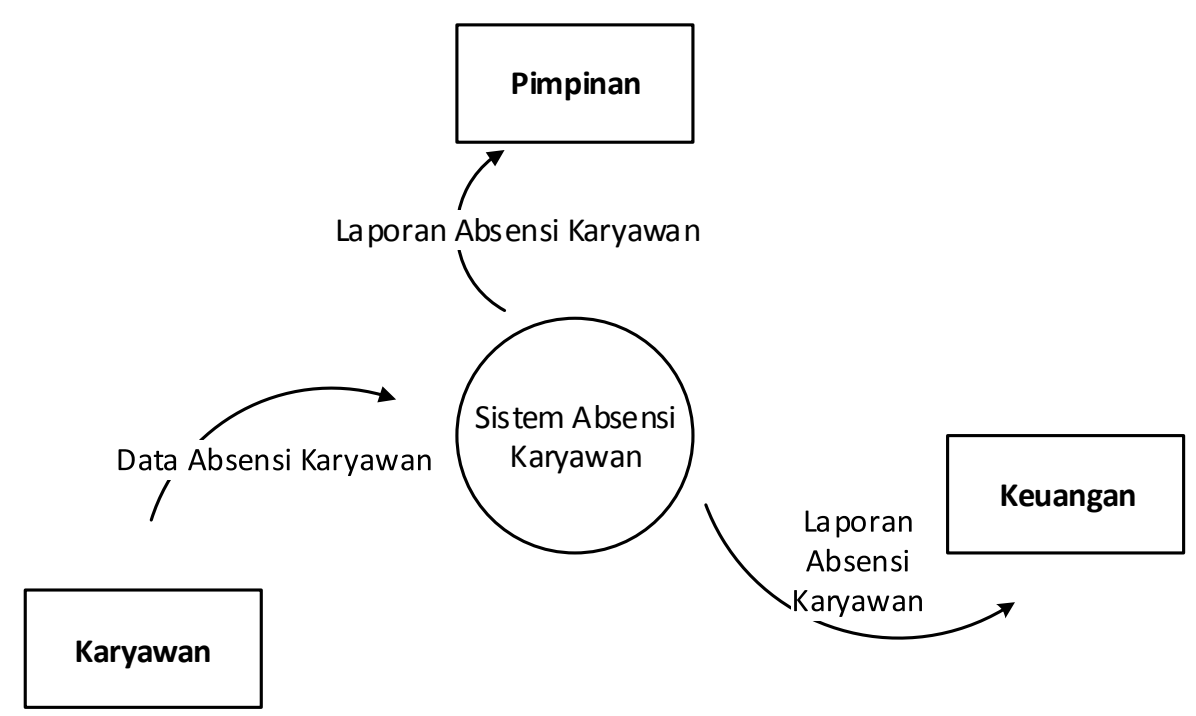

Gambar 3.1 Diagram Konteks sistem yang sedang berjalan

\subsection{Data Flow Diagram}

Data Flow Diagram yang terdapat pada Sistem absensi karyawan yang sedang berjalan adalah sebagai berikut :

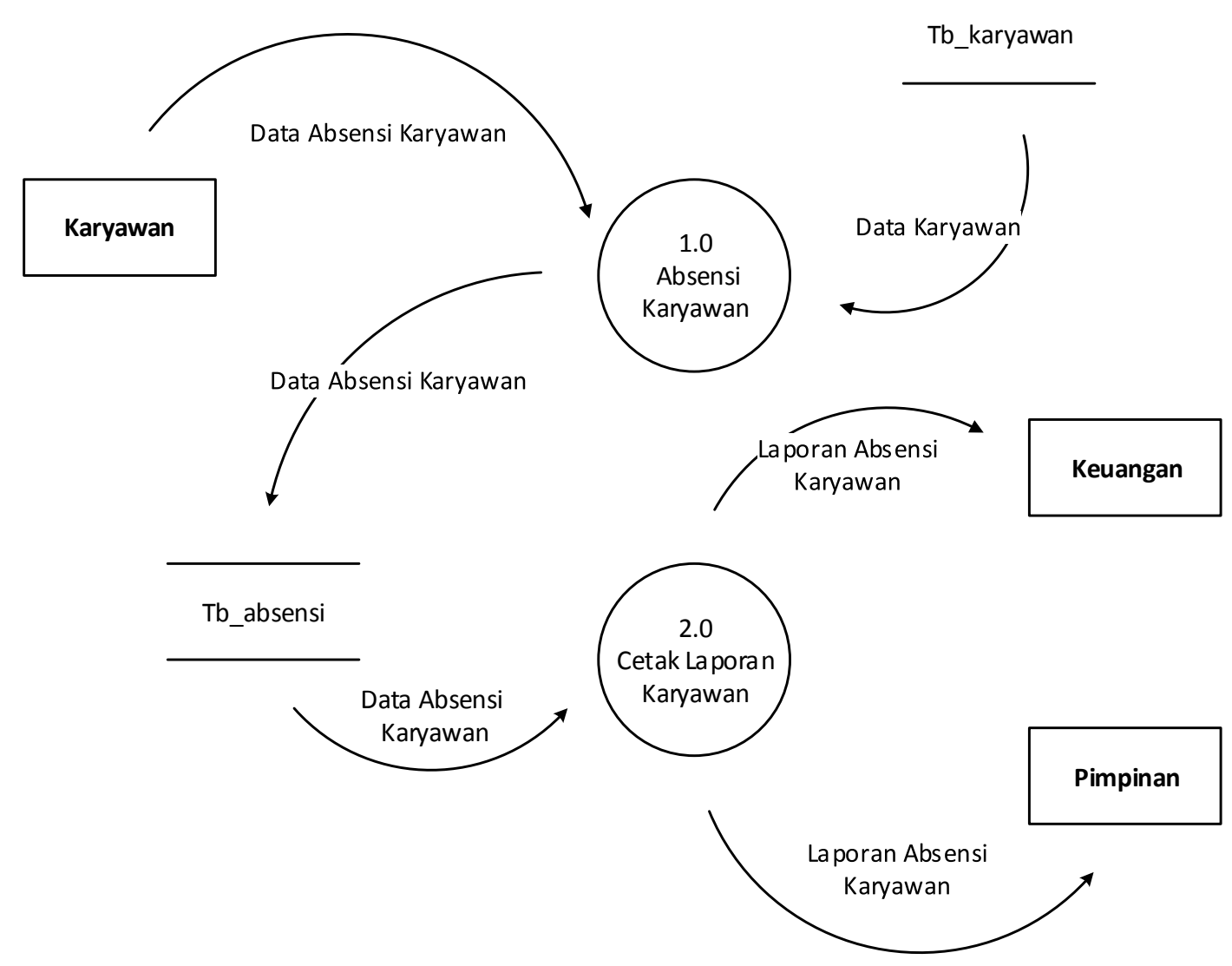

Gambar 3.2 Sistem Yang Sedang Barjalan 


\subsection{Evaluasi Sistem Yang Berjalan}

Dari sistem yang sedang berjalan adalah berupa sistem yang manual dan kurang baik dalam proses mengontrol kehadiran karyawan sehingga didapati karyawan yang kurang disiplin dalam melaksanakan tugas dan tanggung jawab bekerja dalam perusahaan, maka dapat dihubungkan menjadi system tertentu yang bias dipahami dengan modul dan data kehadiran karyawan yang dapat dikelola dengan baik.

\subsection{Usulan Perancangan Sistem}

Perancangan sistem merupakan suatu kegiatan pengembangan prosedur dari proses yang sedang berjalan untuk menghasilkan efektifitas kerja, agar dapat member hasil yang sesuai tujuan yang diharapkan dengan memanfaatkan teknologi dan fasilitas yang tersedia.

\subsection{Tujuan Perancangan Sistem}

Tujuan utama dari perancangan proses sistem secara umum adalah untuk memberikan gambaran secara umum kepada pemakai (user) mengenai sistem yang baru. Perancangan system secara umum merupakan tahap persiapan dari perancangan sistem secara terperinci. Pada tahap perancangan proses, menjelaskan komponen- komponen yang terkait didalam sistem yang dirancang dengan tujuan untuk dikomunikasikan kepada pemakai.

\subsection{Perancangan Prosedur yang Diusulkan}

Prosedur absensi yang diusulkan adalah :

1. Setiap karyawan melakukan absensi setiap pagi hari kerja dan menggesek kartu absensi pada alat absensi yang telah disediakan sistem tersebut akan langsung merekap absensi karyawan siapa-siapa saja yang terlambat dan tidak masuk secara otomatis.

2. Pimpinan perusahaan menerina laporan absensi karyawan setiap bulan sebagai data untuk diolah dalam penilaian kinerja karyawan dalam perusahaan.

\subsection{Perancangan Flow Map yang Diusulkan}

Dalam merancang suatu Flow Map, harus dianalisa prosedur yang sedang berjalan, setelah melakukan analisa terhadap system yang sedang berjalan, maka perlu adanya perancangan aliran dokumen yang dirancang dalam sistem yang baru, dapat dilihat pada gambar dibawah ini. 
Tabel 3.2 Flow Map System Yang Diusulkan

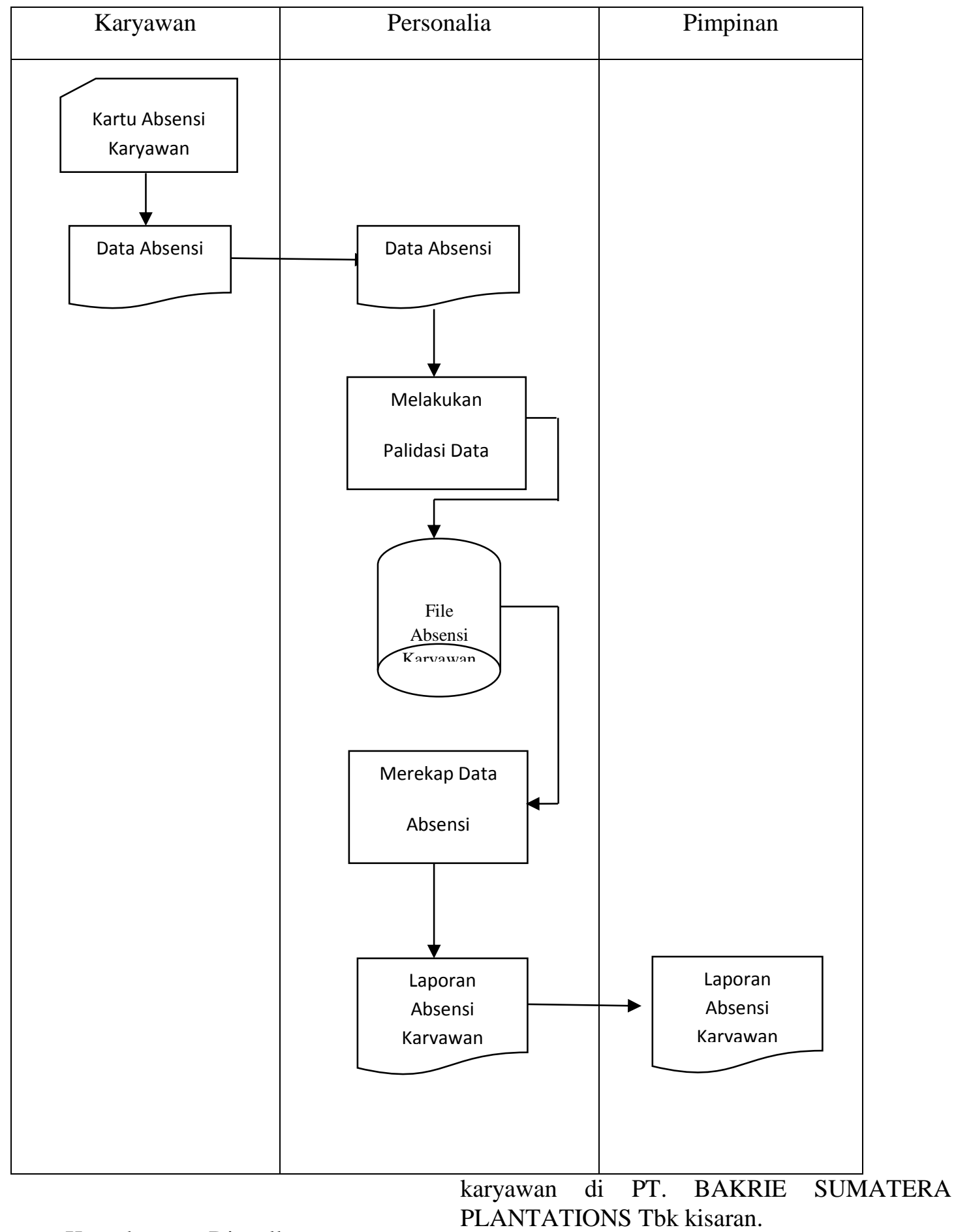

\subsection{Diagram Konteks yang Diusulkan}

Diagram konteks adalah suatu diagram yang menggambarkan suatu arus data sistem. Untuk memahami suatu sistem yang menggambarkan secara keseluruhan, diagram konteks usulan dari sistem informasi absensi 


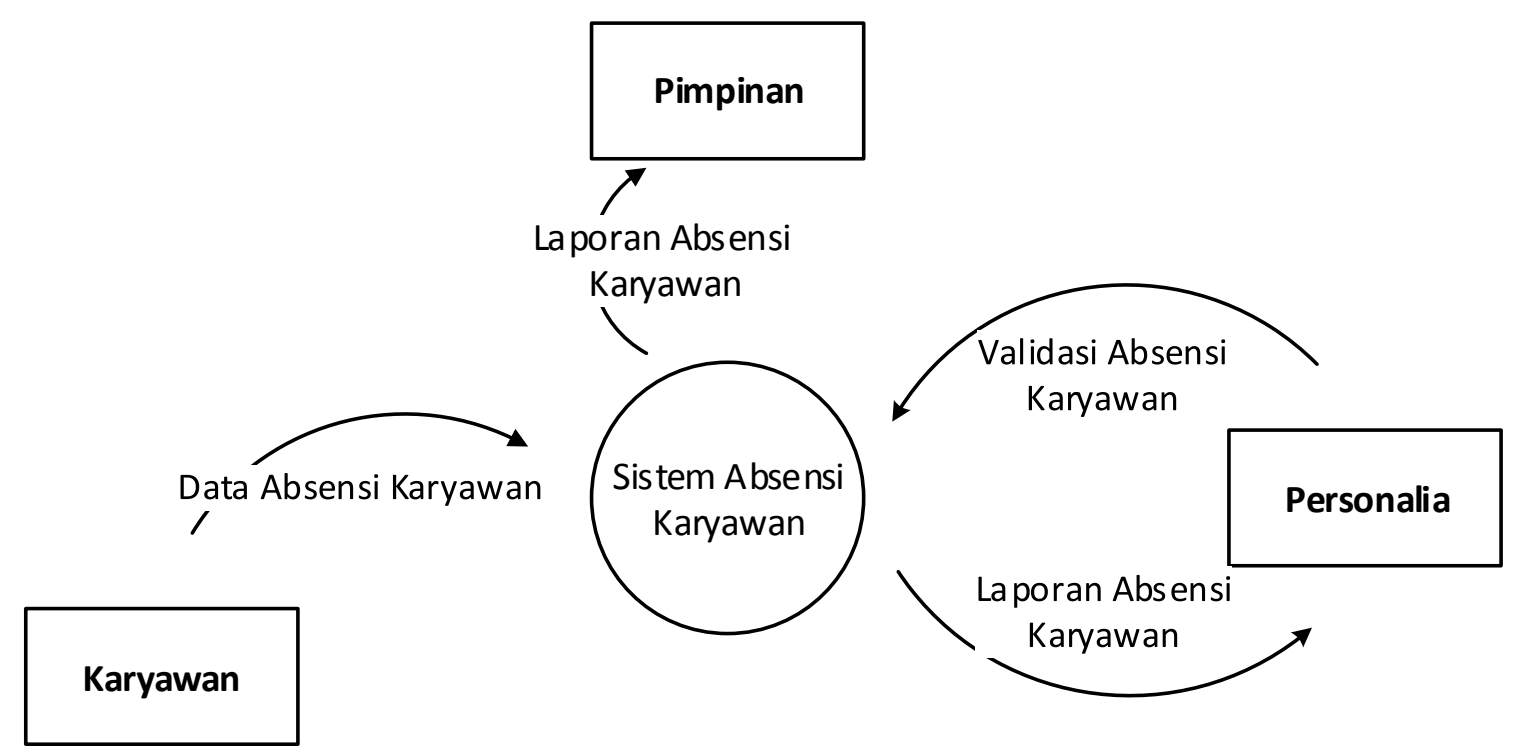

Gambar 3.2 Diagram Konteks sistem yang diusulkan

\subsection{DFD (Data Flow Diagram) yang diusulkan}

Data Flow diagram atau diagram aliran data ini merupakan penjabaran sistem dari diagram konteks, diturunkan menjadi beberapa proses yang terjadi antara entitas yang terlibat dengan sistem. DFD juga memperjelas dokumen-dokumen yang mengalir dalam sistem.
Data Flow diagram usulan dari sistem informasi absensi karyawan di PT. BAKRIE SUMATERA PLANTATIONS adalah sebagai berikut :

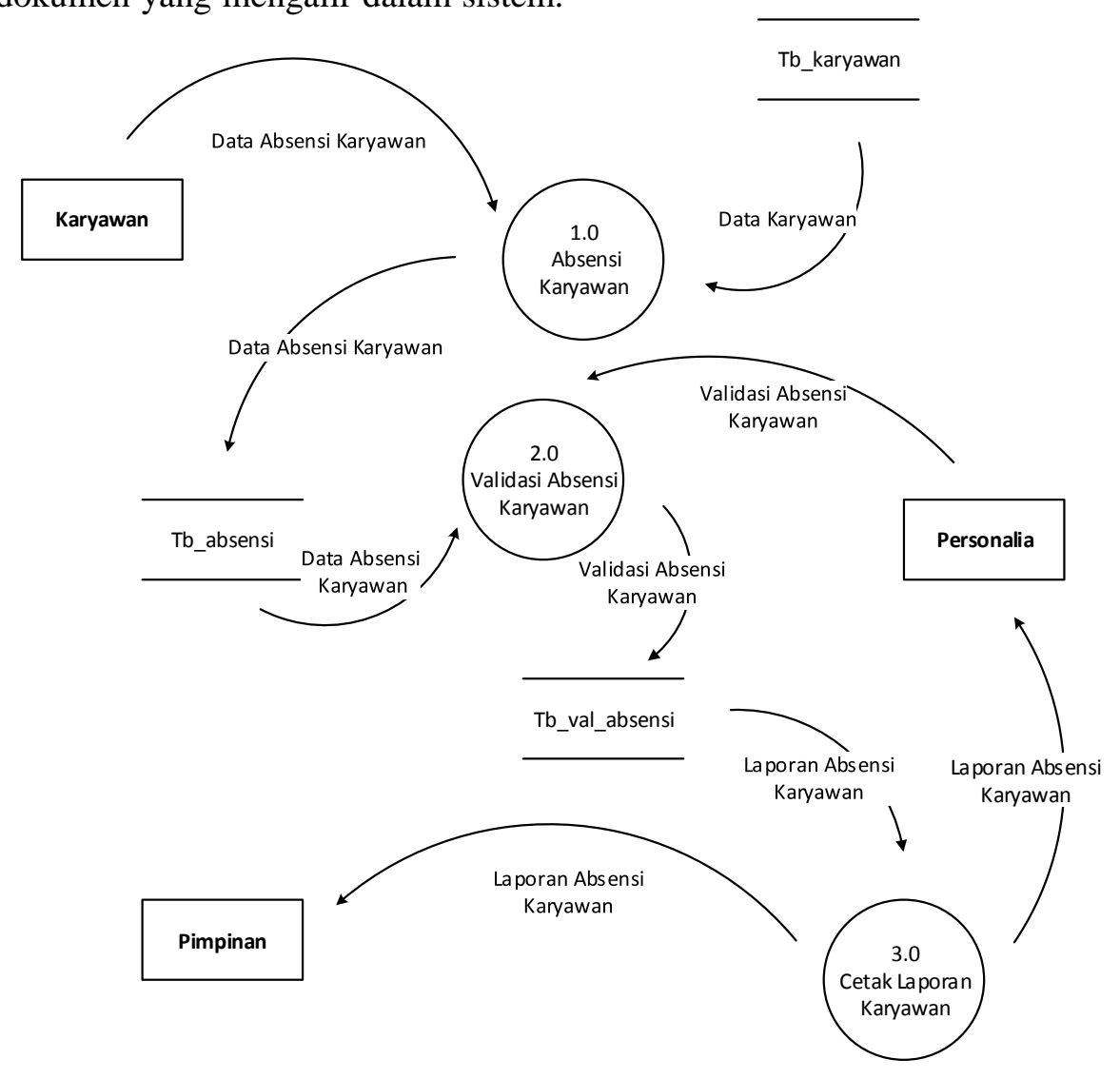

Gambar 3.3 DFD sistem yang diusulkan 


\subsection{Evaluasi Sistem yang diusulkan}

Dari sistem yang baru didapat kelebihan-kelebihan cukup signifikan terutama dalam rekapitulasi perhitungan jumlah hadir dan sistem yang baru dibuat lebih simple karena dalam sistem baru menggunakan kartu gesek yang mana dalam proses ini, karyawan dapat bertindak/berlaku lebih displin karena apabila terlambat beberapa menit sistem ini akan mencetak sesuai dengan keadaan dilapangan tidak dapat dimanipulasi karena rekapitulasi absensi dimonitor oleh HRD/Personal.

\section{KESIMPULAN}

Berdasarkan analisa yang telah dilakukan seperti diatas, maka dapat diambil beberapa kesimpulan sebagai berikut:

a. Adanya proses pengiriman data absensi harian karyawan yang baru, ini dapat mempermudah bagian payroll dalam sistem kerjanya sehingga lebih mudah, cepat dan lebih efisien.

b. Payroll tidak perlu melakukan proses penginputan data lagi melainkan verifikasi data

\section{SARAN}

Dari kesimpulan yang telah dibuat dan dibahas, maka ada beberapa saran yang dapat penulis berikan untuk pengembangan aplikasi. Adapun beberapa saran yang akan disampaikan adalah:

1. Pengembangan program atau sistem aplikasi ini alangkah baiknya dibuat juga pada bagian lapangan, agar data bisa langsung dikirim secara online ke bagian payroll dengan sistem komputerisasi, sehingga tidak perlu menginputkan data lagi satu persatu, dan bagian payroll hanya melakukan pengecekan data saja.

2. Program atau aplikasi ini memang multi user dan alangkah baiknya sub bagian tertentu saja yang mengaksesnya agar kekuatan dan keamanan data dapat terjamin.

\section{DAFTAR PUSTAKA}

[1] Handaya, Soewarno.1980. Pengantar Ilmu Study Dan Manajemen. Jakarta: CV. Haji Mas Agung

[2] Haryanto, Bambang. 2004. Sistem Manajemen Basis Data. Bandung: informatika

[3] Jogiyanto. 2005. Analisa dan Desain Informasi. Yogyakarta : Andi Witarto. 2004. Memahami Sistem Informasi. Bandung: Informatika.

[4] Syafrijal, Melwin. 2010. Pengantar Jaringan Komputer. Yogyakarta: Amikom

[5] Pengantar Absensi diambil dari: http://id.wikipedia.org/wiki/"absensi" (10 oktober 2017)

[6] Pengantar oracle diambil dari : http://id.wikipedia.org/wiki/"oracle" (10 oktober 2017)

[7] Sejarah Bakrie Sumatera Plantations diambil dari: www.bakriesumatera.com/index.php/id/ho me-id-id/sekilas-sejarah (23 oktober 2017) 